\title{
A case of bilateral ear pyogenic granuloma following ear piercing
}

\section{Suvashis Dash, Rakesh Kain}

Department of Burns, Plastic and Maxillofacial Surgery, Vardhman Mahavir Medical College and Safdarjung Hospital, New Delhi, India

Corresponding author: Dr. Suvashis Dash, E-mail: suvashis.dash@gmail.com

Sir,

We are reporting a case a pyogenic granuloma of bilateral ear following piercing of ear. An 18 year old student who has undergone piercing of her ears in a piercing parlor 2 months back. This patient underwent aesthetic piercing of her bilateral superior helix. After 2 weeks of piercing she developed slight swelling and pain. She stopped using her gold ornaments in the pierced holes. She visited her general practitioner who prescribed some antibiotics and analgesic but the symptoms did not subsided. Gradually the area becomes raw. Fleshy red colored wet granulation tissue about 3-5 mm of size present on both side of pierced surface, which bleeds on touch. The patient presented to us after 2 month of piercing. We have planned excision of the granuloma. Excision of lesions along with $2 \mathrm{~mm}$ margin of surround cartilage was done on both sides. Wound was closed primarily. On histopathology report it was found lobular pattern of vascular proliferation with signs inflammation resembling granulation tissue. There was ulceration with loss of epidermis. Stroma has dilated budding capillaries, surrounded by endothelial cells. The histopathology was suggestive of pyogenic granuloma. Wounds have healed without any complications.

Pyogenic granuloma - first described by Antonin Poncet and Dor, in 1897, who named it botryomycosis hominis. It is also called as lobular capillary hemangioma. The name is a misnomer as it is not pus producing or granulomatous; mostly it is seen in children and young adults on head, neck and extremities as a solitary red fleshy lesion that prone to ulceration and bleed on touch. PG is also very common in pregnant women (tumor of pregnancy) usually in oral cavity. Various factors are associated with the development of these lesions, like physical trauma irritation, hormonal factors and medications like oral contraceptives, retinoid and anticancer agents [1].

Post piercing pyogenic granuloma is common in nose but it is a rare presentation in ear. There are few cases of post piercing ear granuloma reported, but bilateral presentation is rare. The cause of pyogenic granuloma post piercing in this case may be continuous irritation or unknown. Prognosis is usually good, with recurrence rate of $16 \%$. On gross feature these are fleshy exophytic lesions, which easily bleed on touch. On microscopy there is lot of capillary and venule with inflammatory stroma. The overlying epithelium is thinned with ulceration. Mature lesion often shows fibromyxiod stroma which separates the lesion in to lobes. Hyperkeratosis and acanthosis may be present. There may be mitotic activity present. In around $10 \%$ of pyogenic granuloma extramedullary hematopoiesis can occur. Presence of myxoid structures in the pyogenic granuloma may be the main cause of recurrence. Differential diagnosis includesinflammatory granulation tissue, other vascular tumors like hemangioendotheliomas, hemangiopericytomas reactive angioendotheliomatosis and Bacillary angiomatosis.

Electrocauterization and curettage (excision), and laser treatment can be used. There are several differential diagnoses for the ear swellings which mimics pyogenic granuloma. Pyogenic granuloma post piercing is one of the uncommon diagnoses [2-4].

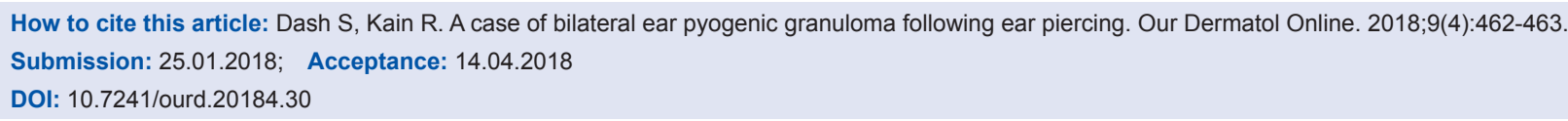




\section{Consent}

The examination of the patient was conducted according to the Declaration of Helsinki principles.

\section{REFERENCES}

1. Thomas J, Sindhu BR. Pyogenic granuloma at ear piercing site: Report of a case. Indian Dermatol Online J. 2014;5:347.

2. Zonunsanga. Pyogenic granuloma treated with continuous wave CO2 laser followed by ultrapulsed CO2 laser ablation. Our
Dermatol Online. 2015;6:160-2.

3. Fernández-Aceñero MJ, Fernández-López P. Granulomatous contact dermatitis to palladium following ear piercing. Indian J Dermatol Venereol Leprol. 2008;74:651.

4. Metts J. Common complications of body piercing. Wes J Med. 2002;176:85

Copyright by Suvashis Dash, et al. This is an open-access article distributed under the terms of the Creative Commons Attribution License, which permits unrestricted use, distribution, and reproduction in any medium, provided the original author and source are credited.

Source of Support: Nil, Conflict of Interest: None declared. 